\title{
FORMULATION AND PHARMACOKINETIC DETERMINATION OF GALLIC ACID IN EMBLICA OFFICINALIS
}

\author{
SANGEETHA S. ${ }^{* 1}$, MALAY K. SAMANTA ${ }^{2}$, KAVITHA R. ${ }^{1}$, REMYA P. N. ${ }^{1}$, SARASWATHI T. S. ${ }^{1}$
}

${ }^{1}$ Department of Pharmaceutics, SRM College of Pharmacy, SRM University, Chennai, Tamil Nadu, India, ${ }^{2}$ Department of Biotechnology, JSS College of Pharmacy, JSS university, Ooty, Tamil Nadu, India

Email: sangeethamadhesh@gmail.com

Received: 03 Nov 2016, Revised and Accepted: 22 Aug 2017

ABSTRACT

Objective: The present work was to formulate oral herbal tablets of Emblica officinalis extract and also with pure gallic acid, further to determine the dosage frequency through pharmacokinetic profiles obtained for the same.

Methods: The Emblica officinalis fruits were suitably extracted and the concentration of gallic acid in Emblica officinalis extract was estimated by HPTLC (High-Performance Thin Layer Chromatography) with a comparison to pure form. Tablets were prepared with extract and synthetic form through direct compression technique by varying the process and formulation parameters. The formulated tablets were administered to rabbit models and their pharmacokinetic profile was studied after withdrawing blood samples through HPLC (High-Performance Liquid Chromatography).

Results: The concentration of gallic acid in Emblica officinalis was found to be 8.21\%. The pre and post compression parameters evaluated for the formulated batches found to be within the pharmacopoeial limits. The in vivo pharmacokinetic studies conducted in rabbit models showed that there were no significant differences with p-value between the pharmacokinetic data obtained for pure and extract gallic acid tablets. The $\mathrm{C}_{\max }$ was found to be $4.59 \pm 0.95 \mu \mathrm{g} / \mathrm{ml}$ in the extract form which was little low when compared to the pure form of $6.38 \pm 1.08 \mu \mathrm{g} / \mathrm{ml}$. The $t_{1 / 2}$ in the extract form was $6.0 \pm 0.33 \mathrm{~h}$, whereas it was $4.92 \pm 0.36 \mathrm{~h}$ in the pure form of gallic acid.

Conclusion: The Emblica officinalis extract tablet showed average $\mathrm{t}_{1 / 2}$ of $6 \mathrm{~h}$, so about every $6 \mathrm{~h}$ one tablet compared to $4 \mathrm{~h}$ of $\mathrm{t}_{1 / 2}$ for pure gallic acid tablet can be the dosing frequency for the rabbit.

Keywords: Emblica officinalis, Gallic acid, Pharmacokinetics, dosing frequency.

(C) 2017 The Authors. Published by Innovare Academic Sciences Pvt Ltd. This is an open access article under the CC BY license (http://creativecommons.org/licenses/by/4.0/) DOI: http://dx.doi.org/10.22159/ijap.2017v9i5.16011

\section{INTRODUCTION}

Herbal drugs have been in use by different civilizations in different parts of the world for centuries to fight a large number of diseases. Many of these are in common use even today. With the emerging interest in the world to adopt and study the traditional system and to exploit their potentials based on different healthcare systems, the evaluation of the rich heritage of the traditional medicine is essential [1]. To reveal the active compounds of herbal medicines, in addition to chemical and pharmacological studies, pharmacokinetic study of herbal medicines is an important and necessary approach to elucidate the status and changes of active components in herbal medicines in the body, to explain and predict a series of events related to their efficacy and toxicity and finally to provide a firm basis for design of reasonable doses of clinical applications and pharmacological experiments [2]. So far, for most herbal medicines some basic and principal pharmacokinetic parameters of the isolated compounds have been reported but they were not linked or compared to the corresponding data in the whole herb and or herbal extract [3]. A significant shortcoming of this approach is that interactions among different ingredients cannot be observed only individual components are investigated, further, more pharmacokinetic data are usually available on only one or two ingredients which in most cases are markers rather than the main active principles in the investigated herbal medicines. This may mislead the interpretation of mechanisms of action, dosage design, and therapeutic monitoring during clinical applications of herbal medicines [4].

With the emerging interest in the world to adopt and study the traditional system and to exploit their potentials based on different healthcare systems, the evaluation of the rich heritage of the traditional medicine is essential. In conventional medicines, most remedies consist of synthetic drug preparation. Since herbal formulations consist of natural plant material and not a synthesized chemical, herbal remedies are less likely to cause unpleasant side effects than conventional pharmaceutical drugs. Thus, herbal remedies are précised safer, gentler and lower costing than conventional drugs [5-7].

Emblica Officinalis is a botanical that has been used since ancient times in Hindu and Ayurvedic traditional medicine. The fruit of the plant has been traditionally used for medicinal purposes and contains the active constituent gallic acid. The active constituent is an antimutagenic, anticarcinogenic and anti-inflammatory agent $[8,9]$.

This paper reports a comparative pharmacokinetic study on the formulation of oral herbal tablets of Emblica officinalis in extract form which was compared with the pharmacokinetic profile of the pure gallic acid formulation, which may be a reference to increase the efficacy, safety and quality for further research. Knowledge of herbal pharmacokinetics can provide valuable information to aid Practitioners in prescribing herbs safely and effectively. It may also enable useful predictions for dosing frequency based upon their half-life.

\section{MATERIALS AND METHODS}

\section{Materials}

Emblica officinalis fruit was purchased from Annai Agencies (voucher no: AA4621), Ooty, Nilgiri District, Tamilnadu and authenticated by a Botanist from Central Council for Research in Ayurveda and Siddha, Tirunelveli, Tamilnadu. Gallic acid was purchased from Preet Remedies (Baddi). All other chemicals were of analytical grade.

\section{Extraction of gallic acid}

The Emblica officinalis fruits obtained were washed cut into pieces and the seeds were removed. Then the fruit was dried in shade for about $15 \mathrm{~d}$ and powdered. The powdered Emblica officinalis (10 gm) was extracted for $24 \mathrm{~h}$ with $100 \mathrm{ml}$ of methanol using a shaker at 25 ${ }^{\circ} \mathrm{C}$ and filtrated through $0.45 \mathrm{~mm}$ membrane filter paper. The residue was then extracted twice with $100 \mathrm{ml}$ methanol. The combined methanolic extracts were concentrated by using a water 
bath maintained at $40{ }^{\circ} \mathrm{C}$. The residue was freeze-dried and then stored in an amber colored air-tight container at $40{ }^{\circ} \mathrm{C}$, before further use $[8,9]$.

\section{Quantification of the extract by HPTLC}

The extract of gallic acid was quantified using standard drugs at $273 \lambda \max$ of (CAMAC Linomat, iv, Switzerland) after the development of pre coated plates of $4 * 10 \mathrm{~cm}$ size (silica gel 60F 254, 6. Merck).

\section{Preparation of samples}

The extract (100 mg) was weighed and dissolved in methanol. The flask was shaken for $30 \mathrm{~min}$ and then filtered through Whatman filter paper and the final volume was made up to $10 \mathrm{ml}$ with methanol.

\section{Preparation of standard solutions}

Weighed $100 \mathrm{mg}$ of extract was dissolved in $10 \mathrm{ml}$ of methanol. From this $1.0 \mathrm{ml}$ was diluted to $20 \mathrm{ml}$ with methanol to produce 0.5 $\mathrm{mg} / \mathrm{ml}$. The standard drugs solution were also prepared at a concentration of $0.5 \mathrm{mg} / \mathrm{ml}$ with methanol in a similar manner and used for the analysis.

\section{Application of standard and sample solutions}

For the application of the solutions, pre-coated plates of $4 \times 10 \mathrm{~cm}$

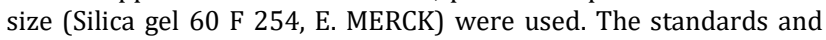
the sample solutions were applied on different tracks of the plate. A thin band of $6 \mathrm{~mm}$ width was applied using Linomat IV (automatic TLC applicator, CAMAG, Switzerland).

\section{Chromatogram development and densitometric scanning}

After the development of the chromatogram through twin-trough chamber, the plates were taken out, dried and observed under UV light. The suitable solvent system selected for the quantification of gallic acid was toluene: ethyl acetate: formic acid in the ratio of 7:5:1 $\mathrm{v} / \mathrm{v}$ for the development of chromatogram. The developed plates were scanned using densitometer at $273 \mathrm{~nm}$ wavelength. The quantification of the gallic acid was calculated concerning standard solution [10].

\section{Formulation and evaluation of tablets}

Tablets of both synthetic gallic acid (300 mg) and the extract (equivalent to $3.2,8.4 \mathrm{mg}$ of Gallic acid) were compressed (rotary tablet compressor, ten stations, Rimek, Ahmedabad, India) using 121 $\mathrm{nm}$ standard concave punches by direct compression technique with varying the process and formulation parameters. All the powder mass was passed through the BSS- 80 mesh and geometrically mixed in a polyethylene bag for $10 \mathrm{~min}$. Then lubricant (aerosil) was added and mixed for an additional $5 \mathrm{~min}$ and then compressed. Prior the compression, the powder mixture evaluated for angle of repose, bulk density, compressibility index and drug content. Table 1 gives the formula of different batches $[11,12]$.

\section{Precompression parameters}

The powder mixtures were studied for an angle of repose, bulk and tapped density, compressibility index, and drug content. The angle of repose was determined by funnel method using the below formula where $h$ and $r$ were the height and radius of the powder cone.

Angle of repose $=\tan -1(\mathrm{~h} / \mathrm{r})(1)$

Table 1: Formula for the formulation of Emblica officinalis extract and gallic acid tablets

\begin{tabular}{llll}
\hline S. No. & Ingredients & Pure gallic acid tablets (mg) & Emblica officinalis extract tablets (mg) \\
\hline 1 & Gallic acid & 300 & - \\
2 & Emblica officinalis Extract & - & 400 (Equivalent to 32.84 mg of Gallic Acid) \\
3 & Starch 1500 & 150 & 50 \\
4 & MCC & 26 & 26 \\
5 & Croscarmellose & 20 & 20 \\
6 & Aerosil & 4 & 4 \\
\hline
\end{tabular}

The bulk and tapped density were determined by taking the known quantity of slightly shaken powder mixture. These samples were, introduced to $50 \mathrm{ml}$ measuring cylinder to record the bulk density. This is then allowed to fall under its weight onto a hard surface from the height of $2.5 \mathrm{~cm}$ at $2 \mathrm{sec}$ interval. The tapping continued until no further change in volume was observed. The density was calculated based on the weight of powder to the volume occupied by it. The compressibility index was determined by analyzing the quantity of quinine extracted into phosphate buffer $\mathrm{pH} 3$ spectroscopically at $\lambda \max$ of $225 \mathrm{~nm}$ and expressed regarding percentage.

$$
\text { Compressibility index }(\%)=100(T D-B D) \div T D(2)
$$

Where TD and BD represent tapped and bulk density respectively.

\section{Post-compression parameters}

Post compression parameters like weight variation $(n=20)$, drug content $(\mathrm{n}=10)$, friability $(\mathrm{n}=$ tablet to whole weight of $6.2 \mathrm{~g})$, disintegration time $(\mathrm{n}=6)$ and hardness was determined. The test for post compression parameters except hardness performed as per IP 2007. The drug content estimated for individual tablets. The hardness and friability were calculated using Monsanto hardness tester (Cadmach, Ahmedabad, India) and friability testing apparatus (Indian equipment, Mumbai, India). Then represents the number of tablets used for the test [13-15].

\section{In-vitro drug release}

The dissolution medium consisted of $900 \mathrm{ml}$ of phosphate buffer $\mathrm{pH}$ 7.2, and the study was carried out for $90 \mathrm{~min}$ for the developed formulation maintained at $37^{\circ} \mathrm{C} \pm 0.5^{\circ} \mathrm{C}$. The drug release at different time intervals was measured by HPLC (Shimadzu) at $225 \lambda$ max. It made clear that none of the ingredients used in the matrix formulations interfered with the assay. The release studies conducted in triplicate and the mean values plotted versus time [16-18].

\section{Pharmacokinetic studies}

\section{Animals}

Experiments were carried out on New-Zealand white rabbits of either sex $1.5 \pm 0.2 \mathrm{~kg}$ (mean $\pm \mathrm{SD})$. The animals had overnight fasted before treatment but had free access to tap water. None subject was receiving any other drug at least two weeks before commencement of the study and no other drug permitted throughout the duration of the study. They randomly assigned into six groups $(3$ animals per group). Two groups received Gallic acid tablets, and two groups received Emblica officinalis extract tablets and one group as control. All experiments adhered to the institutional animal's ethics committee (JSSCP/IAEC/Projects/01/2008-09).

\section{Administration and Collection of blood samples}

The dose for the study taken was $35 \mathrm{mg}$ and $70 \mathrm{mg}$ of gallic acid from gallic acid tablets and extract tablets respectively calculated according to body weight and body surface area of rabbit with the help of conversion factor with the absolute human dose. The rabbits received the dose orally through an intragastric tube as $0.3 \% \mathrm{w} / \mathrm{v}$ CMC suspension. Blood samples $(1 \mathrm{ml})$ were collected in heparinized tubes from the marginal ear vein at $0,0.5,1,2,4,6,8,12,24 \mathrm{~h}$ after the drug administration. The samples centrifuged at $3500 \mathrm{rpm}$ for $10 \mathrm{~min}$ to separate the plasma and they were transferred into airtight containers and stored at $-20 \pm 0.2^{\circ} \mathrm{C}$ until analyzed [20]. 


\section{Preparation of plasma samples}

The gallic acid extracted from plasma samples $(1 \mathrm{ml})$ obtained from study subjects by the addition of $200 \mu \mathrm{l}$ of perchloric acid to precipitate plasma proteins. The resulting solution was vortexed for $5 \mathrm{~min}$ and centrifuged at $4000 \mathrm{rpm}$ for $10 \mathrm{~min}$. The supernatant layer was separated and analyzed by using Shimadzu gradient HPLC system [10].

\section{Determination of gallic acid in plasma}

The gallic acid extracted from plasma samples and the supernatant layer was separated and analyzed by using Shimadzu gradient HPLC system with LC-20 AD 230V Solvent delivery system (Pump), Manual Injector $25 \mu$ l (Rheodyne), SPD-M20A 230V Photo diode array detector and LC solutions data station. Separation achieved at room temperature on a Phenomenex Gemini C18 (250x4.6 mm i.d., $5 \mu$ ) column. The mobile phase was a mixture of water and acetonitrile 97.5:2.5 v/v. The flow rate was $1.0 \mathrm{ml} / \mathrm{min}$. The detection was done at $254 \mathrm{~nm}$ using SPD 20AD Diode Array Detector.

\section{Statistics}

All data expressed as mean value \pm standard deviation (SD). Statistical analysis was performed using ANOVA test (Tukey's test). Mean differences considered as statistically significant at a level of $p<0.05$.

\section{RESULTS AND DISCUSSION}

The extract of gallic acid from Emblica officinalis fruit done with methanol at $25{ }^{\circ} \mathrm{C}$ for $24 \mathrm{~h}$ then filtered. The residue was then extracted twice with $100 \mathrm{ml}$ methanol then the methanolic extracts were combined and concentrated at $40{ }^{\circ} \mathrm{C}$, then freeze dried. The obtained extract was quantified for gallic acid by HPTLC with a comparison to the peak area obtained for $0.5 \mathrm{mg} / \mathrm{ml}$ methanolic solution of pure Gallic acid. The application volume of extract and the synthetic solution was $5 \mu \mathrm{l}$ respectively.

The pre-coated plates developed using mobile phase consisting of toluene: ethyl acetate: formic acid in the ratio of 7:5:1 v/v was scanned by densitometer at the wavelength of $273 \mathrm{~nm}$. The result is shown in table 2, with the obtained peak area at Rf value of $0.73 \pm 0.2$ it estimated that $8.21 \%$ of the gallic acid is present in the Emblica officinalis extract.

Table 2: Quantification of gallic acid in the herbal extract by HPTLC

\begin{tabular}{lllll}
\hline S. No. & Sample & Rf & Peak area & Gallic acid (\%w/w) \\
\hline 1 & Extract & 0.73 & 1975.3 & \\
2 & Gallic acid & 0.17 & 1741.5 & 8.21 \\
\hline
\end{tabular}

$\mathrm{Rf}=$ Retention factor

The pure drug and the extract powder mixed with excipients in the geometrical pattern for $10 \mathrm{~min}$ and to confirm the uniform distribution of the drug the degree of mixing was carried. The drug content was 98.57 and $92.26 \%$ in case of pure drug and extract respectively. The further mixing led to demixing in the case of the pure drug, and no significant change was seen in the extract.

The angle of repose gives a qualitative assessment of internal and cohesive-frictional forces. All the batches had an angle of repose less than $31^{\circ}$ indicating good flow potential. The size and shape of the particles reflect the density of the material. The density is directly proportional to the number of spherical particles present whereas inversely to the size of the particles. As the value of compressibility is less than $15 \%$ in all the cases, the granules produced the adequate flow and stable packing. Table 3 shows the results of precompression parameters.

Tablets of synthetic and extract were compressed by direct compression technique and the table 4 displaces their post compression parameters. The hardness of all the formulations was between 5.92 to $5.45 \pm 0.78 \mathrm{~kg}$. The other parameters such as average weight, friability disintegration was found to be within limits. The drug content also showed more than $90 \%$ in both pure and extract tablets. MCC was used as binder cum diluent in the formulation as is widely used and croscarmellose used as the super disintegrant. The aerosil was used at the concentration of $2 \%$ as it can nullify the use of additional lubricant as it can serve both as glidant and lubricant in a case of direct compression. Various trials have been done, and only the optimized batch formula is given in table No 1 . With the satisfactory post compression parameters, the in vitro release studies were carried out in $900 \mathrm{ml}$ of Phosphate buffer $\mathrm{pH}$ 7.2. The in vitro dissolution study was carried out for $90 \mathrm{~min}$ and the drug release at different time intervals was measured by HPLC at $225 \mathrm{~nm}$. The in vitro release graph is shown in fig. 1 [16-18]. It was observed at the end of $90 \mathrm{~min}$ the release was about $99 \%$ in pure gallic acid tablets and $88 \%$ in extract tablets.

A single dose study, for two concentrations (drug equivalent to 35 $\mathrm{mg}$ and $70 \mathrm{mg}$ ) of Emblica officinalis extract and pure gallic acid, were carried out in five groups, containing three rabbits in each group, for each concentration of the formulations. The plasma samples were analyzed by reverse phase HPLC (Shimadzu UFLC LC20AD) with chromatographic conditions as water and acetonitrile in the ratio of $97.5: 2.5 \% \mathrm{v} / \mathrm{v}$ as mobile phase and phenomena.

Table 3: Precompression evaluations for Emblica officinalis Extract and pure gallic acid blend

\begin{tabular}{llll}
\hline S. No. & Parameters & Pure gallic acid blend & Emblica officinalis extract blend \\
\hline 1 & Angle of repose $\left({ }^{0}\right.$ degree $)$ & $26.45 \pm 1.56$ & $30.74 \pm 1.98$ \\
2 & Bulk density (g/cm3) & $0.48 \pm 0.05$ & $0.52 \pm 0.07$ \\
3 & Tapped density (g/cm3) & $0.59 \pm 0.07$ & $0.62 \pm 0.08$ \\
4 & Compressibility (\%) & $13.49 \pm 1.45$ & $14.58 \pm 1.94$ \\
5 & Drug content (\%) & $98.57 \pm 1.78$ & $94.26 \pm 1.53$ \\
\hline
\end{tabular}

Values represent mean $\pm S D, n=3$.

Table 4: Post compression evaluations for tablets

\begin{tabular}{llll}
\hline S. No. & Parameters & Emblica officinalis extract tablets & Pure gallic acid blend tablets \\
\hline 1 & Average weight (mg) & $499.25 \pm 2.96$ & $497.12 \pm 2.56$ \\
2 & Hardness (Kg/cm2) & $5.92 \pm 0.25$ & $5.45 \pm 0.78$ \\
3 & Friability (\%) & $0.362 \pm 0.035$ & $0.826 \pm 0.07$ \\
4 & Disintegration (minutes) & $10.33 \pm 0.82$ & $3.45 \pm 0.69$ \\
5 & Drug content (\%) & $90.45 \pm 1.39$ & $97.72 \pm 1.83$ \\
\hline
\end{tabular}

Values represent mean $\pm S D, n=3$. 


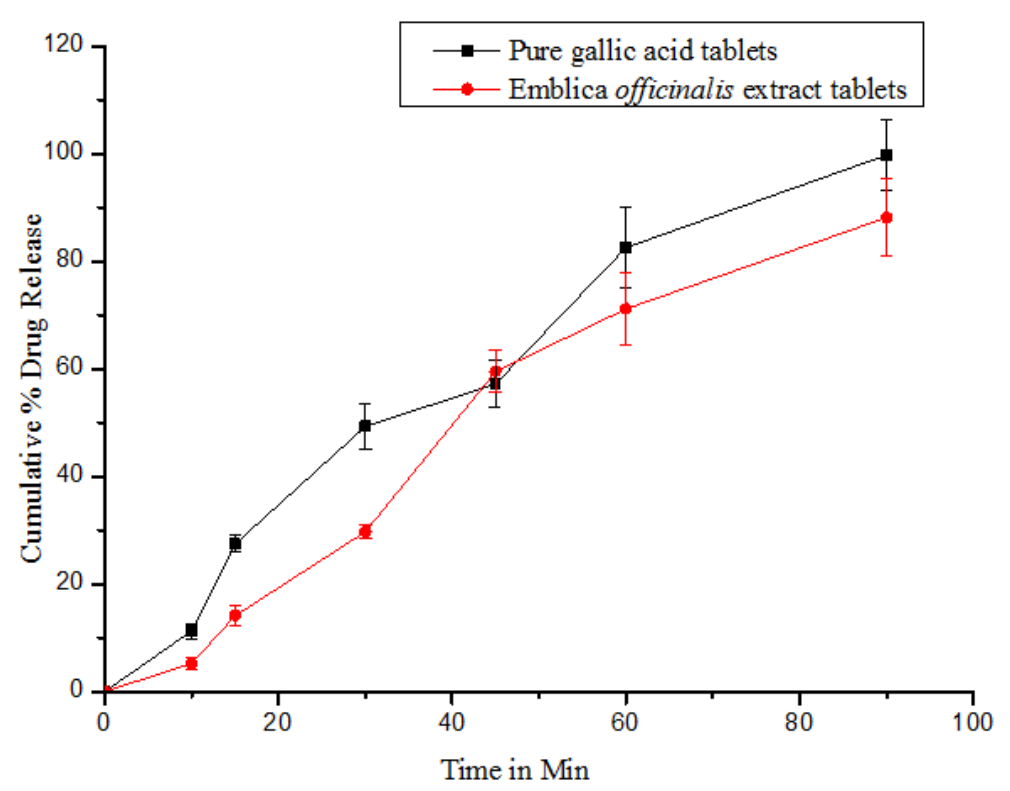

Fig. 1: In vitro dissolution plots of Emblica officinalis extract and Gallic acid tablets, Results are given in mean of triplicate

Table 5: Pharmacokinetic parameters of Emblica officinalis extract and pure gallic acid tablets

\begin{tabular}{llll}
\hline S. No. & Parameters & Average of two doses & Pure gallic acid \\
\cline { 3 - 4 } & & Emblica officinalis extract & $6.38 \pm 1.08$ \\
\hline 1 & $\mathrm{C}_{\max }(\mu \mathrm{g} / \mathrm{ml})$ & $4.59 \pm 0.95$ & $1.75 \pm 0.78$ \\
2 & $\mathrm{~T}_{\max }(\mathrm{h})$ & $1.5 \pm 0.53$ & $0.140 \pm 0.03$ \\
3 & $\mathrm{~K}_{\mathrm{eli}}\left(\mathrm{h}^{-1}\right)$ & $0.116 \pm 0.38$ & $4.92 \pm 0.36$ \\
4 & $\mathrm{t}_{1 / 2}(\mathrm{~h})$ & $6.0 \pm 0.33$ & $79.80 \pm 1.75$ \\
5 & $\mathrm{AUC}_{(0-24)}(\mu \mathrm{g} . \mathrm{h} / \mathrm{ml})$ & $29.65 \pm 1.01$ & $82.38 \pm 1.40$ \\
6 & $\mathrm{AUC}(0-\infty)(\mu \mathrm{g} . \mathrm{h} / \mathrm{ml})$ & $32.60 \pm 1.02$ & No \\
7 & $\left.\mathrm{Lag} \mathrm{Time}_{\mathrm{t}}\right)$ & No & \\
\hline
\end{tabular}

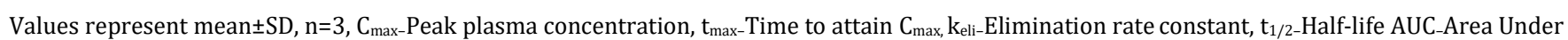
Curve, $\left(\mathrm{t}_{0}\right)$-Lag time

Gemini phase C18 (250x4.6 mm, i.d. $5 \mu)$ as a stationary phase. The flow rate of mobile phase set at $1 \mathrm{ml} / \mathrm{min}$, and the samples detected by LC solutions as the data station at $225 \mathrm{~nm}$. The quantification of the chromatogram was performed using peak area ratios (response factor) of the drug to the internal standard. Table 5 provides the various PK parameters estimated by PK1 and PK2 software. The values present in the table represent the average values of two doses. From the results, it observed that all the Pharmacokinetic parameters determined showed a slight increase with the pure gallic acid tablets, but half-life was found to be comparatively high in extract tablets. The pharmacokinetic data obtained for the pure and the extract showed no significant difference which confirmed by application of one-way ANOVA followed by Tukey test [19-22].

\section{DISCUSSION}

After the quantification of the Emblica officinalis extract, it was observed that $8.21 \%$ of the gallic acid is present in the Emblica officinalis extract. The preparation of tablets involves two basic techniques a) direct compression b) wet compression. The techniques have their advantages and disadvantages. The limitation of wet granulation is its cost. It is an expensive process because of labor, time, equipment, energy and space requirements, Loss of material during various stages of processing; Stability may be the major concern for moisture sensitive or thermo labile drugs, an inherent limitation of wet granulation is that any incompatibility between formulation components made us opts for direct compression. The leeway of the technique was minimized loss of mixing quantity for moisture sensitive material and improved disintegration since powder particles are not bonded together by a binder. The excipients in this study are common, used to formulate tablets. The MCC was used as a diluent, croscarmellose as the super disintegrant, aerosil as a glidant and lubricant. In the process of product development, some of the chemicals were added, omitted or varied in concentrations. The MCC is used as binder cum diluent in the formulation as is widely used in both the cases. But some researchers reported that MCC could sustain the release of the drug, to overcome this Croscarmellose used as the super disintegrant at the concentration of $5 \% \mathrm{w} / \mathrm{w}$. At the concentration of $26 \mathrm{mg}$, the MCC provided the satisfactory post compression results in both pure and extract form. The aerosol was used at the concentration of $2 \% \mathrm{w} / \mathrm{w}$ which can nullify the use of additional lubricant as it can serve both as glidant and lubricant. The other post compression parameters like Average weight, friability, disintegration, and drug content were found to be within limits. As the hardness increased the disintegration time prolonged, the increase in hardness may be due to inbuilt nature of the extract. With the optimized batch, the in vitro release was found to be satisfactory. The pharmacokinetic parameters for both the extract and the pure formulation were, evaluated directly after oral administration of them into the stomach of rabbits. The study was, carried to evaluate the difference in the PK parameters between the two formulations. The pharmacokinetic data obtained for the pure and the extract showed no significant difference.

\section{CONCLUSION}

The pharmacokinetic data obtained for the pure and the extract had no significant difference which was confirmed by application of oneway ANOVA followed by Tukey test. The pharmacokinetic data obtained for pure and extract Gallic acid shows no significant difference in Cmax at Tmax. The Emblica officinalis extract tablets 
showed an average $t_{1 / 2}$ of $6 \mathrm{~h}$ and about every $6 \mathrm{~h}$ one tablet (equivalent to a min of $35 \mathrm{mg}$ of gallic acid) compared to $4 \mathrm{~h}$ of $\mathrm{t} 1 / 2$ for pure Gallic acid tablet can be administered to the selected animal model as the dosing frequency. Further multiple dose studies are required to determine the exact dosage regimen.

\section{CONFLICT OF INTERESTS}

Declared none

\section{REFERENCES}

1. Swati SP, Saluja AK. Traditional medicines: sources of new drugs. Pharm Times 2002;34:17-23.

2. Samanta MK, Mukherjee PK, Prasad MK, Suresh B. Development of natural products. Eastern Pharm 2000;3:23-7.

3. Tamizhmani T, Mukherjee PK, Manimaran S, Suresh B. Indian herbal drug development: problems and prospects. Pharm Times 2002;34:13-4.

4. Mahady GB. Global harmonization of herbal claims. J Nutr 2001;131:1120-3.

5. Aoyagi M, Aneta M, Hayashi T, Shibata T, Hatakeyama Y. Preparation and chemical evaluation of Cnidium officinale. Hokkaidoritsu EiseiKen Kyu Soho 2001;51:97-9.

6. Bylaite E, Venskutonis RP, Roozen JP. Influence of harvesting time on the composition of volatile components in different anatomical parts of lovage (Levisticum officinale koch). J Agric Food Chem 1998;46:3735-40.

7. Gray E. Antioxidant potential of ferulic acid. Free Radical Boil Med 1992;13:435-48.

8. Scartezzini P, Antognoni F, Raggi MA, Poli F, Sabbiani C. Vitamin $\mathrm{C}$ content and antioxidant activity of the fruit and the Ayurvedic preparations of Emblica officinalis Gaertn. J Ethnopharmacol 2006;104:113-8.

9. Vani T, Rajani M, Sarkar S, Shishoo CJ. Antioxidant property of the ayurvedic formulation triphala and its constituents. Int J Pharmacol 1997;35:313-7.

10. Sethi PD. HPLC quantitative analysis of pharmaceutical formulations. New Delhi, CBS Publishers, and distributors; 2000. p. 1-200.
11. Lieberman, Lachman, JB Schwartz. Pharmaceutical dosage forms. Vol. I. Tablets, Edited by HH Marcel Dekker: New York; 1989. p. 592.

12. Modasiya MK, Prajapati BG, Patel VM, Shah DA. Design and characterization of fast disintegrating tablets of piroxicam. Int J Pharm Tech Res 2009;1:353-7.

13. Gohel MC, Pranav DJ. A review on co-processed directly compressible Excipients. J Pharma Sci 2005;8:76-93.

14. LY Galichet, Cellulose. Microcrystalline in the handbook of pharmaceutical excipients. $5^{\text {th }}$ edition. London UK Pharmaceutical Press; 2006. p. 132-5.

15. Aulton ME. Pharmaceutics, The Science of Dosage Form Design. London, England: Churchill Livingston; 1988. p. 305-608.

16. United States pharmacopeia, 24/National Formulary USP Conventional Inc. Rockville, MD; 2000;19:546-7.

17. Pharmacopoeia of India, New Delhi, Ministry of Health and Family Welfare, Government of India, Controller of Publications; 1996.

18. Singla N, Gupta GD, Kholi K, Singla AK. A discriminatory and bio relevant dissolution test method for simvastatin drug products; 2009. p. 11-3.

19. Karan RS, Bhargava VK, Garg SK. Effect of trikatu, an ayurvedic prescription, on the pharmacokinetic profile of rifampicin in rabbits. J Ethnopharmacol 1999;64:259-64.

20. Ghosh MN. Fundamentals of experimental pharmacology. 3rd ed. Hilton Company. Kolkata; 2005. p. 192.

21. Rowland T. Clinical Pharmacokinetics: Concepts and Application. $2^{\text {nd }}$ ed. Lea and Febizer; 1989. p. 407-512.

22. Kucuk A, Kadýoglu Y, Celebi F. Investigation of the pharmacokinetics and determination of tramadol in rabbit plasma by a high-performance liquid chromatography-diode array detector method using liquid-liquid extraction. J Chromatogr B 2005;1:203-8.

\section{How to cite this article}

- Sangeetha S, Malay K Samanta, Kavitha R, Remya PN, Saraswathi T. S, Formulation and pharmacokinetic determination of gallic acid in Emblica officinalis. Int J Appl Pharm 2017;9(5):9-13. 